\title{
Impact of COVID-19 Pandemic on Migraine Patients, Observations from a Tertiary Care Centre in South India
}

\author{
Bincy Baby ${ }^{1}$, Rhea Anne Roy ${ }^{2}$, John K. John ${ }^{3}$ \\ 1,2, 3 Department of Neurology, Believers Church Medical College and Hospital, Tiruvalla, Kerala, India.
}

\section{ABSTRACT}

\section{BACKGROUND}

Primary headache especially migraine ranks among the top 20 causes of the disease burden as per the years lived with disability (YLD) criteria. ${ }^{1}$ Stress due to many factors during the COVID-19 pandemic can worsen the migraine symptoms and reduce the therapeutic response. ${ }^{2,3}$ In this study, we aimed to investigate this impact on migraine frequency and severity on medical care, in addition to overall psychosocial health and specific COVID-19 (Coronavirus Disease 2019) concerns among migraine patients.

\section{METHODS}

A questionnaire based telephonic survey was used to collect details about the impact of COVID-19 on patients with migraine who visited our outpatient clinic from $1^{\text {st }}$ January 2019 to $31^{\text {st }}$ December 2019. Telephonic interview was carried out by the investigators from July $5^{\text {th }}$ to August $1^{\text {th }}$ of 2021.

\section{RESULTS}

A total of 320 patients participated in the survey. Women constituted $79.7 \%$ of the study population and, $39.7 \%$ were between $40-60$ years while $34.1 \%$ were between 20-40 years of age. In comparison to the pre-pandemic period, $56.9 \%$ of patients reported increase in the severity of migraine and $55.9 \%$ reported increase in the number of headache-days. Difficulties in accessing headache medications was reported by $73.4 \%$ and, $75.3 \%$ were not able to follow their medication schedule. Only $57.2 \%$ were able to access specialist care during the pandemic. Overuse of analgesics was reported by $15.9 \%$ of participants in the pre-pandemic period, while it increased to $37.8 \%$ after the pandemic. Sleep disturbances, anxiety and depression were reported by $47.2 \%$ and increase in screen-time exposure was mentioned by $41.9 \%$.

\section{CONCLUSIONS}

COVID-19 pandemic has caused a significantly negative impact on patients with migraine. Well planned strategies should be implemented to ensure availability of quality care for patients with migraine, with emphasis on psychosocial well-being.
Corresponding Author: Dr. John K. John, Associate Professor, Department of Neurology, Believers Church Medical College and Hospital, Tiruvalla, Kerala, India. E-mail: johnkjohn101@gmail.com

DOI: $10.14260 /$ jemds $/ 2022 / 72$

How to Cite This Article: Baby B, Roy RA, John JK. Impact of COVID 19 pandemic on migraine patients, observations from a tertiary care centre in South India. J Evolution Med Dent Sci 2022;11(02):375-379, 10.14260/jemds/2022/72

Submission 20-01-2022,

Peer Review 25-01-2022,

Acceptance 04-02-2022,

Published 07-02-2022.

Copyright (c) 2022 Bincy Baby et al. This is an open access article distributed under Creative Commons Attribution License [Attribution 4.0 International (CC BY 4.0)]

\section{KEY WORDS}

COVID-19, Migraine, Primary Headache. 


\section{BACKGROUND}

The COVID-19 pandemic is considered to be the most crucial global health calamity of the century and the greatest challenge faced by humankind since the $2^{\text {nd }}$ World War. In December 2019, a new infectious respiratory disease emerged in Wuhan, Hubei province, China and was named by the World Health Organization as COVID-19. On March 11, 2020, the World Health Organization declared COVID-19 as a pandemic. The first case of COVID-19 in India was reported on 30 January 2020.4 India currently has the largest number of confirmed cases in Asia. As of May 2021, India has the second-highest number of confirmed cases in the world (after the United States) with nearly 20 million reported cases of COVID-19 infection and 249,992 deaths. The effect of COVID-19 infection and related lockdown in patients with different ailments is substantially more when compared to general population. Moreover, health-care systems and health-care workers around the world have been overwhelmed with this novel public health crisis. Neurologists are facing a huge challenge in providing quality care to their patients with chronic diseases, in particular those with headache, while working to minimize the spread of COVID-19 outbreak. $^{5}$

Headache is a common symptom and collectively, headache disorders are one of the most common nervous system disorders. The global prevalence of headache is $48.9 \%$ in the general population and is more common in women. Headache can be extremely debilitating and can have significant impact on an individual's quality of life, imposing huge costs to healthcare and indirectly to the economy. Patients with primary headache are highly vulnerable to pandemic due to the associated changes in lifestyle, medical care and other aspects of treatment. The effect of COVID-19 pandemic and related lockdown on patients with primary headache are catastrophic. From heightened levels of psychosocial stress, social isolation and disruption of daily activities, to several COVID-19-specific concerns-patients with migraine can suffer from losing their earlier therapeutic response, especially with cancellation of face-to-face visits and procedural treatments. ${ }^{5}$ Even though many countries attempted to adapt to the situation by implementing various approaches such as telemedicine clinic, telephonic consultations and other online services, not all countries were successful in delivering quality care.

The present study intended at investigating the "realworld" impact of the COVID-19 pandemic and related lockdown on migraine frequency and severity, on delivery of medical care, medication compliance, overall psychosocial health, and specific COVID-19 concerns among patients with migraine who presented to our outpatient headache clinic.

\section{METHODS}

A cross-sectional questionnaire based telephonic survey was used to investigate the impact of COVID-19 on patients with migraine. It was conducted through a structured telephonic interview in a sample of patients who visited our outpatient clinic from $1^{\text {st }}$ January 2019 to $31^{\text {st }}$ December 2019 . The study was approved by the institutional research board and Institutional Ethics Committee.
Inclusion criteria for the study were patients who were above 18 years of age, seen in the outpatient clinic of the Department of Neurology at the Believers Church Medical College, Thiruvalla, Kerala between 1st January 2019 to 31st December 2019, and had a diagnosis of migraine. Patients who were found to have any other types of primary headache or secondary headache were excluded from the study

Telephonic interview was carried out by the investigators from the period of July 5th to August 15th of 2021. The questionnaire was administered in either English or Malayalam as per the participant's preference. After explaining the purpose of the survey, verbal consent was obtained at the beginning of the interview during the telephonic interview. Those who declined consent were excluded from the study.

The following variables were included in the questionnaire. 1. Socio-demographic variables such as age, gender, educational level, marital status, occupation, working during the pandemic. 2 . Headache related variables like onset, medical / procedural treatments, emergency department visits, changes in headache frequency during COVID-19 pandemic, changes in headache severity during COVID-19 pandemic. 3. Medication related variables such as availability of the drugs, compliance to treatment, medications overuse, use of alternative / traditional medicine 5. Associated symptoms for perceived depression and anxiety, and dietary disturbances and 6. COVID-19-related variables like infection with the virus, specific worries and concerns during the pandemic, screen time exposure, exercise during the pandemic, use of hand sanitizers, use of mask etc.

\section{Statistical Analysis}

Data was analysed using SPSS statistical software. (IBM, New York). Chi-square test was used to determine the association between categorical variables and t-test was used for continuous variables. Significance of the obtained results was set at $\mathrm{p}<0.05$ level.

\section{RESULTS}

A total of 320 patients satisfying the inclusion criteria completed the survey.

\section{Demographic Details}

Out of the 320 participants, majority were females $(79.7 \%)$. 52 (16.3\%) were less than 20 years, 109 (34.1\%) between 20 - 40 years, 127 (39.7\%) between 40 - 60 years, and 32 were above 60 years of age. Among the respondents, 255 (79.7\%) were females. 232 were married and 164 had university education. The demographic details are listed in Table 1.

\section{Headache during the Pandemic}

Most participants reported an increase in headache days per month and headache severity during the pandemic (55.9\% and $56.9 \%$ respectively). [Table 2] Of them, $34(10.6 \%)$ reported the increase as significant, $120(37.5 \%)$ as moderate and $56(17.5 \%)$ as mild. About $52(16.3 \%)$ had to visit the 
emergency department to get acute treatment for their headache. This included patients who had severe headache and those who had prolonged headache.

\section{Medication Related Variables}

Compliance to medication was present in only $24.7 \%$ while $73.4 \%$ reported having difficulty in accessing medications, and $25.3 \%$ reported using homeopathic, ayurvedic, traditional medicines or alternative methods of treatment for treating headache during the pandemic. Analgesic use increased significantly during the pandemic, as evidenced by the 121 (37.8\%) participants who reported analgesic overuse during the pandemic compared to 51(15.9\%) before the pandemic.

\section{Disruptions in Medical Care}

During the pandemic, patients with migraine reported facing obstacles due to difficulty in access, forced social isolation, and encountering a health system that was overwhelmed. Among our 320 respondents, 52 (16.3\%) reported having very severe attacks necessitating emergency department (ED) visits. More than half of the respondents $(57.2 \%)$ made contact with their neurologists during the lockdown period through various methods. Among them, 80 patients $(25.0 \%)$ reported visiting the hospital, 37 patients (11.6\%) used telephone, and 66 patients $(20.6 \%)$ used telemedicine facility.

\section{Effect of Change in Lifestyle and Working Habits}

Disturbances in sleeping habits were reported by nearly half of participants (47.2\%), eating disturbances by 107 and disturbances in regular exercise habits by $45.6 \%$ participants.

Wearing a medical mask and regular use of sanitizers are important methods used for preventing the spread of COVID19. However, the use of a mask and some fragrant sanitizers may cause aggravation of headache in some individuals. Of the respondents, few reported worsening of headache due to use of face mask and sanitizers, 75 (23.4\%) and 12 (3.8\%) respectively. Out of the 320 participants, only one third of them were employed during the pandemic (33.4\%) and the remaining either worked from home or were unemployed. Nearly half of the respondents reported an increase in screentime exposure during the pandemic (134)

\section{Effect of Psychological Factors}

Symptoms of anxiety and depression were experienced by 151 participants (47.2\%) and their major concern during the pandemic was the possibility of infection with COVID-19 (41.3 $\%)$. Financial problems, fear of losing job etc were also other concerns mentioned.

\section{COVID-19 Infection}

Among 320 patients, only 12 (3.8 \%) were COVID-19 positive and of them only 8 reported worsening of headache during infection.

\section{Associations}

We assessed statistically significant association between various variables using Chi-Square Test. Significant associations were found between increase in migraine frequency and difficulty in getting medications, symptoms of anxiety and depression, change in sleeping habits, change in eating habits and screen time exposure. However, there was no statistically significant association between increase in headache frequency, age, gender or use of alternative medications. Although we evaluated the association between difficulty in getting medications and non-compliance, there was none.

\begin{tabular}{|c|c|c|}
\hline & Variable & No. and Percentage \\
\hline \multirow{2}{*}{$\begin{array}{l}\text { Increase in headache days per } \\
\text { month compared to pre- } \\
\text { pandemic period }\end{array}$} & Yes & $179(55.9 \%)$ \\
\hline & No & $141(44.1 \%)$ \\
\hline \multirow{2}{*}{$\begin{array}{l}\text { Increase in headache severity } \\
\text { compared to pre-pandemic }\end{array}$} & Yes & $182(56.9 \%)$ \\
\hline & No & $138(43.1 \%)$ \\
\hline \multirow{4}{*}{$\begin{array}{l}\text { Description of increase in } \\
\text { headache }\end{array}$} & Significant & 34 (10.6\%) \\
\hline & Moderate & $120(37.5 \%)$ \\
\hline & Slight & $56(17.5 \%)$ \\
\hline & Did not increase & $110(34.4 \%)$ \\
\hline \multirow{2}{*}{$\begin{array}{l}\text { Medication adherence during the } \\
\text { pandemic }\end{array}$} & Yes & $79(24.7 \%)$ \\
\hline & No & $241(75.3 \%)$ \\
\hline \multirow{2}{*}{$\begin{array}{l}\text { Difficulty in getting headache } \\
\text { medication }\end{array}$} & Yes & $235(73.4 \%)$ \\
\hline & No & $85(26.6 \%)$ \\
\hline \multirow{2}{*}{$\begin{array}{l}\text { Overuse of analgesics before } \\
\text { pandemic }\end{array}$} & Yes & $51(15.9 \%)$ \\
\hline & No & $269(84.1 \%)$ \\
\hline \multirow{2}{*}{$\begin{array}{l}\text { Overuse of analgesics during } \\
\text { pandemic }\end{array}$} & Yes & $121(37.8 \%)$ \\
\hline & No & $199(62.2 \%)$ \\
\hline \multirow{2}{*}{$\begin{array}{l}\text { Use of homeopathic /ayurveda/ } \\
\text { traditional/ alternative medicines } \\
\text { for headache }\end{array}$} & Yes & $81(25.3 \%)$ \\
\hline & No & $239(74.7 \%)$ \\
\hline \multicolumn{3}{|c|}{ Distribution of survey respondents based on medical care related variables } \\
\hline \multirow{3}{*}{$\begin{array}{l}\text { Visited emergency due to severe } \\
\text { headache attack }\end{array}$} & Variable & Number and Percentage \\
\hline & Yes & $52(16.3 \%)$ \\
\hline & No & $268(83.8 \%)$ \\
\hline \multirow{2}{*}{$\begin{array}{l}\text { Communicated with treating } \\
\text { neurologist during pandemic }\end{array}$} & Yes & $183(57.2 \%)$ \\
\hline & No & $137(42.6 \%)$ \\
\hline \multirow{3}{*}{ Method of communication } & Visited hospital & $80(25.0 \%)$ \\
\hline & Telemedicine clinics & $66(20.6 \%)$ \\
\hline & Telephone & $37(11.6 \%)$ \\
\hline \multicolumn{3}{|c|}{ Lifestyle and working habits during pandemic } \\
\hline \multirow{2}{*}{$\begin{array}{c}\text { Disturbance in sleeping habits } \\
\text { during pandemic }\end{array}$} & Yes & $151(47.2 \%)$ \\
\hline & No & $169(52.8 \%)$ \\
\hline \multirow{2}{*}{$\begin{array}{c}\text { Disturbance in eating habits } \\
\text { during pandemic }\end{array}$} & Yes & $107(33.4 \%)$ \\
\hline & No & $213(66.6 \%)$ \\
\hline \multirow{2}{*}{$\begin{array}{c}\text { Disturbance in exercise habits } \\
\text { during pandemic }\end{array}$} & Yes & $146(45.6 \%)$ \\
\hline & No & $174(54.4 \%)$ \\
\hline \multirow{2}{*}{$\begin{array}{l}\text { Worsening of headache due to } \\
\text { use of sanitizers }\end{array}$} & Yes & $12(3.8 \%)$ \\
\hline & No & $308(96.3 \%)$ \\
\hline \multirow{2}{*}{$\begin{array}{l}\text { Worsening of headache due to } \\
\text { use of mask }\end{array}$} & Yes & $75(23.4 \%)$ \\
\hline & No & $245(76.6 \%)$ \\
\hline \multirow{2}{*}{ Employed during pandemic } & Yes & $107(33.4 \%)$ \\
\hline & No & $213(66.6 \%)$ \\
\hline Increase in screen-time exposure & Yes & $134(41.9 \%)$ \\
\hline during pandemic & No & $186(58.1 \%)$ \\
\hline Distribution of respondents base & sed on effect of psycholc & ogical factors \\
\hline Symptoms of anxiety and & Yes & $151(47.2 \%)$ \\
\hline depression during pandemic & No & $169(52.8 \%)$ \\
\hline & $\begin{array}{l}\text { Social / financial / } \\
\text { family problems }\end{array}$ & $70(21.9 \%)$ \\
\hline & $\begin{array}{l}\text { Increased headache } \\
\text { severity / frequency }\end{array}$ & $40(12.5 \%)$ \\
\hline $\begin{array}{l}\text { Greatest fears and concerns } \\
\text { during pandemic }\end{array}$ & $\begin{array}{l}\text { Possibility of COVID-19 } \\
\text { infection }\end{array}$ & $132(41.3 \%)$ \\
\hline & Losing job & $12(3.8 \%)$ \\
\hline & $\begin{array}{l}\text { Unavailability of } \\
\text { medication }\end{array}$ & $2(0.6 \%)$ \\
\hline & Other concerns & $64(20.0 \%)$ \\
\hline COVID-19 related variables & & \\
\hline & $\begin{array}{l}\text { Infection with COVID- } \\
19\end{array}$ & Percentage and Value \\
\hline & Yes & $12(3.8 \%)$ \\
\hline & No & $308(96.3 \%)$ \\
\hline If infected, whether headache & Yes & $8(2.5 \%)$ \\
\hline increased or not & No & $4(1.20 \%)$ \\
\hline
\end{tabular}




\begin{tabular}{|c|c|c|}
\hline & Variable & Number and Percentage \\
\hline \multirow{4}{*}{ Age } & $<20$ & $52(16.3 \%)$ \\
\hline & $20-40$ & $109(34.1 \%)$ \\
\hline & $40-60$ & $127(39.7 \%)$ \\
\hline & $>60$ & $32(10.0 \%)$ \\
\hline \multirow{2}{*}{ Gender } & Male & $65(20.3 \%)$ \\
\hline & Female & $255(79.7 \%)$ \\
\hline \multirow{5}{*}{ Occupation } & Full-time job & 127 (39.7 \%) \\
\hline & Homemaker & $104(32.5 \%)$ \\
\hline & Student & $59(18.4 \%)$ \\
\hline & Retired & $13(4.1 \%)$ \\
\hline & I don't work & $17(4.1 \%)$ \\
\hline \multirow{3}{*}{ Marital status } & Married & $232(72.5 \%)$ \\
\hline & Single & $81(25.3 \%)$ \\
\hline & Widow & $7(2.2 \%)$ \\
\hline \multirow{3}{*}{ Education } & University & $164(51.4 \%$ \\
\hline & High school & 138 (43.3 \%) \\
\hline & Primary school or less & $17(5.3 \%)$ \\
\hline
\end{tabular}

\section{DISCUSSION}

The present study was a questionnaire-based survey among migraineurs from a single center and we observed that more than half of the participants had a negative impact from the COVID-19 pandemic. There were also increases in both frequency of attacks and severity of headache when compared to the pre-pandemic period.

During the lockdown which was declared in most of the countries after the onset of the pandemic, many health sytems introduced various changes in the way outpatient medical care was delivered. In many hospitals there was rapid shift to telehealth which poses certain challenges such as difficulty in communication and clinical examination. It is possible that this had an adverse effect on treatment decisions. Difficulty in accessing a neurologist for care may have been a barrier for patients with migraine in getting proper treatment. All this would have had a significant impact on the quality of life of patients with migraine.

Indeed, our survey revealed statistically significant associations between increase in migraine frequency and difficulty in getting medications, symptoms of anxiety and depression, change in sleeping habits and screen time exposure.

Migraine attacks are thought to occur as a result of natural fluctuations in neuronal excitability. ${ }^{3}$ Various trigger factors are considered to contribute to precipitating an attack, by facilitating the neuronal excitability. Several such trigger factors are known, which include emotional factors like anxiety and panic. Several studies have documented the psychosocial impact of COVID-19 on patients with chronic diseases. 6,7 Psychological distress among migraineurs during the pandemic was found to be much higher than those without migraine. ${ }^{8}$

The marked anxiety and depressive symptoms during the pandemic could be partly associated with the rapidly increasing number of covid cases and the fear of getting infected. It could also be associated with economic related stress, social distance restrictions, travel restrictions and changes in daily life all contributing to feeling of loneliness. ${ }^{9}$ Loneliness itself has been shown to be associated with proinflammatory states, cardiovascular disease, neurodegenerative disease and increased risk of mortality. ${ }^{10}$ The prevalence of headache increases in people with fewer confidants and intimate relationships. ${ }^{11}$
A study from China showed increased frequency of migraine attacks and the attention paid to media coverage of COVID-19 outbreak as the two major risk factors for increased psychological distress after the outbreak of the pandemic. ${ }^{8}$ In our study also $12.5 \%$ participants mentioned increased headache severity and frequency as a concern and fear of COVID-19 infection was reported as the most important cause for psychological stress. Social and financial problems were also reported as important factors contributing.

It is fairly clear that migraine attack itself is a cause for increased stress, thus increasing the severity and frequency of migraine and forming a vicious circle.

A significant number of participants in the study mentioned change in life style and working habits during the pandemic such as disturbances in sleep, changes in eating and exercise habits. An increase in screen-time exposure during the pandemic was observed in our study.

Several studies have shown significant increase in prevalence of sleep disturbance after the outbreak of COVID19 pandemic. A meta-analysis of 44 published studies showed that the prevalence of sleep problems during COVID-19 is high and affected about $40 \%$ of the general population and also among health workers. ${ }^{12}$ The prevalence is much higher among those with active COVID-19. In our study disturbances in sleeping habit was reported by about $47.2 \%$.

Poor sleep quality is associated with greater migraine frequency. ${ }^{13}$ Apart from anxiety due to fear of COVID-19 infection, the high prevalence of sleep disturbances is also associated to changes in sleep wake habits, poor practice of sleep hygiene like delayed bedtime, lights off time and sleep on-time. The influence of these factors is likely to vary depending on the quarantine and lockdown rules in different regions.

About $23 \%$ attributed worsening of headache to use of mask during the pandemic. Some studies had previously reported face mask associated headaches. During the 2003 severe acute respiratory syndrome (SARS) epidemic in Singapore, face mask associated headache was studied among health care workers with a prevalence rate of $37.3 \% .{ }^{14}$ The pathogenesis of this headache is thought to have multiple contributing factors including mechanical factors, hypoxemia, hypercarbia or associated stress. ${ }^{15}$

In our study more than $50 \%$ of patients reported increase in headache frequency and severity. This is similar to the observations in other studies. However, it is interesting to note that some studies have shown a reduction in headache severity and frequency among migraineurs after the onset of the pandemic. In a study from Netherlands, a reduction in migraine days and in improvement in general well-being were observed among migraine patients during lockdown compared to the period prior to lock down. This was attributed to measures implemented to improve migraine disability during lock down period, such as working from home, scaling down demanding social lives and freedom to choose how to organize one's time. The authors concluded that intelligent lockdown measures can improve migraine disability despite the potential negative effects of COVID-19 and lockdown. ${ }^{16}$ Similar reduction in migraine severity was reported in a study from Italy and the authors attributed it to less triggers as a result of less work. ${ }^{17}$ 


\section{CONCLUSIONS}

Our study showed that there was significantly negative impact of COVID-19 on migraineurs. We found that a significant number of patients had increase in severity and frequency of headache. The risk factors included lack of communication with the treating physician, difficulty in getting medications, sleep disturbance and increased levels of anxiety and depression. Poor compliance with treatment and increase in analgesic overuse was also observed. More research is required to validate and implement strategies during the pandemic to ensure continued delivery of high-quality patient care. Optimizing tele-medicine in headache care and strategies to prioritize the patient's overall well-being during the pandemic would be areas to focus on, while moving forward.

\section{REFERENCES}

[1] GBD 2016 Disease and Injury Incidence and Prevalence Collaborators. Global, regional, and national incidence, prevalence, and years lived with disability for 328 diseases and injuries for 195 countries, 1990-2016: a systematic analysis for the GlobalBurden of Disease Study 2016. Lancet 2017;390(10100):1211-59.

[2] Szperka CL, Ailani J, Barmherzig R, et al. Migraine care in the era of COVID-19: clinical pearls and plea to insurers. Headache 2020;60(5):833-42.

[3] Charles A. The pathophysiology of migraine: implications for clinical management. Lancet Neurol 2018;17(2):17482.

[4] India, the most infected by COVID-19 among Asian countries, leaves Turkey behind. Hindustan Times. 29 May 2020.

[5] Al-Hashel JY, Ismail II. Impact of coronavirus disease 2019 (COVID-19) pandemic on patients with migraine: a webbased survey study. J Headache Pain 2020;21:115.
[6] Chudasama YV, Gillies CL, Zaccardi F, et al. Impact of COVID-19 on routine care for chronic diseases: a globalsurvey of views from healthcare professionals. Diab Metab Syndr 2020;14(5):965-7.

[7] Dubey S, Biswas P, Ghosh R, et al. Psychosocial impact of COVID-19. Diabetes Metab Syndr 2020;14(5):779-88.

[8] Ma M, Fang J, Li C et al. The status and high risk factors of severe psychological distress in migraine patients during nCOV-2019 outbreak inSouthwest China: a crosssectional study. J Headache Pain 2020;21(1):100.

[9] Cacioppo JT, Cacioppo S, Capitanio JP, et al. The neuroendocrinology of social isolation. Ann Rev Psychol 2015;66:733-67.

[10] Holt-Lunstad J, Smith TB, Baker M, et al. Loneliness and social isolation as risk factors for mortality: ametaanalytic review. Perspect Psychol Sci 2015;10(2):227-37.

[11] Raggi A, Giovannetti AM, Quintas R, et al. A systematic review of the psychosocial difficulties relevant to patients with migraine. J Headache Pain 2012;13(8):595-606.

[12] Lin YK, Lin GY, Lee JT, et al. Associations between sleep quality and migraine frequency: a cross-sectional casecontrol study. Medicine (Baltimore) 2016;95(17):e3554.

[13] Medic G, Wille M, Hemels ME. Short- and long-term health consequences of sleep disruption. Nat Sci Sleep 2017;9:151-61.

[14] Lim EC, Seet RC, Lee KH, et al. Headaches and the N95 face-mask amongst healthcare providers. Acta Neurol Scand 2006;113(3):199-202.

[15] Ong JJY, Bharatendu C, Goh Y, et al. Headaches associated with personal protective equipment - a cross-sectional study among frontline healthcare workers during COVID19. Headache 2020;60(5):864-77.

[16] Verhagen IE, van Casteren DS, de Vries Lentsch S, et al. Effect of lockdown during COVID-19 on migraine: a longitudinal cohort study. Cephalalgia 2021;41(7):86570.

[17] Parodi IC, Poeta MG, Assini A, et al. Impact of quarantine due to COVID infection on migraine: a survey in Genova, Italy. Neurol Sci 2020;41(8):2025-7. 